\title{
O SIGNO ENTRE O TEXTO E O CONTEXTO (PROJETO DE UMA ANÁLISE INTEGRAL)
}

\author{
, Carlos Alberto da Fonseca
}

\section{PROPOSIÇĀO}

Quando o homem falou, atribuiu a conceitos coletivos uma imagem sonora arbitrária, mas que lhe servia para a comunicação e lhe permitia a enunciação dos processos desencadeados pela concatenação de idéias antes apenas mentalizadas: o contexto social em que vivia fornecera-lhe conceitos que foram acoplados (porque anteriores) a formas sonoras. Quando a mera comunicação cotidiana não lhe bastou, e lhe surgiu a necessidade da expressão estética, o homem utilizou os mesmos elementos para a elaboração de textos artísticos, em que as "palavras" eram manejadas de maneira a estabelecer relações recíprocas e, ao mesmo tempo, afastando-se da utilização prática do código lingüístico estabelecido, concretizar idéias imaginadas e imagens idealizadas só possíveis por proposições motivadas: uma motivação social ao nível da necessidade da arte, que acarretou o uso motivado dos elementos da fala na elaboração das obras literárias. As obras, a princípio existentes apenas na memória, um dia foram escritas: então o homem descrbrira uma outra espécie de suporte formal para seus elementos de fala. Mas, existente como manifestação oral ou como atividade de escr.ta, a motivação intrínseca manifestada na manipulação das "palavras" constituintes da obra foi a responsável por uma espécie de intertextualidade social — uma intercontextualidade — responsável, por sua vez, pelas sucessivas traduções interlinguais, intralinguais ou inter-semióticas (in TODOROV, 1970, p. 44). Desta maneira, o contexto, ao qual se assimilavam as obras escritas (e as antes mantidas apenas pela alternativa do som), ao mesmo tempo em que se reforçava pelas transformações de sentido das "palavras", pelos empréstimos conseguidos ao nível dos substratos lingüísticos e pelos novos sentidos conseguidos através do encadeamento das próprias "palavras" no texto, o contexto se sobrecarregava de duas funções. Uma delas é a de fornecer novas significações: neste caso o texto passa a ser um sociofato, na med da em que é produzido não apenas no meio social, mas também por um 
indivíduo que se sobressai e representa as idéias pessoais ou do grupo. A segunda é a de recolher as significações: neste caso, cada indivíduo ou todo o grupo recebe o sentido emanado do texto. As duas funçōes consolidam as significações e as colocam (recentes e antigas) em disponibilidade por meio de um repertório cada vez mais aumentado. Mas, para a elaboração do texto, o homem se valeu de matéria do contexto: desta maneira, o contexto se oferece ao texto, que o devolve de uma outra maneira: real, mas ficcionalizado; crível, mas imaginado. Entre o real e crível e o ficcionalizado e imaginado, há mediação lingüística: na medida em que tornam fictício o real, às "palavras" motivadas se convertem numa nova língua, um novo código - uma linguagem que fala consigo mesma dentro do texto; na medida em que tornam imaginado aquilo que era crível, as "palavras" se aproximam do objeto contextual, evocando-o. Aqui está o cerne da questão: há duas realidades (o texto e o contexto), mas sua única poss.bilidade de existência estética é o fato de que se valem dos elementos da língua.

Quando um primeiro homem escreveu sobre como escrever, escreveu o primeiro manual de como escrever sobre o que foi escrito. A partir daí, ou foi analisada a linguagem do texto, ou o contexto evocado, ou a língua instrumentada no texto. As análises estruturalistas, as perspectivas sociocontextuais-psicológicas-históricas e semióticas/semiológicas fornecem visões sempre parciais da obra analisada. Seria possível uma visão que, partindo do texto e estruturando por desestruturação sua língua e linguagem, abordasse aspectos contextuais, a partir desta mediação lingüística, e depois se reportasse novamente ao texto, estabelecendo, então, a recursividade entre o objeto, o evocado por ele e a natureza do instrumento utilizado? Tentarei discutir esta análise integral, comentando, também, as visões parcials. As conclusões estão implícitas, na medida em que a discussão sobre a possibilidade da análise integral se encarrega de, mostrando seus estatutos recursivos, apresentar, também, a parcialidade das outras visadas críticas. Pode ser que, ao final do exposto, a atividade analítica proposta se revele senão utópica pelo menos exigente. Mas é a exposição da inquietação experimentada antes e depois da escrituração de um texto.

\section{O TEXTO - UMA FALA MEDIATIZADA.}

A obra - uma ficção e duas realidades: o texto, matéria formal que presentifica algo além dele; o contexto, substância exarada pelo texto, e que o preserva como ficção, e o espaço onde ele se realiza. Entre os dois, uma aventura para tornar dito o imperceptível e percebido o indizível. Configuração, representação, imitação, verossimilhan- 
ça, reprodução; o reflexo e o espelho: quase tudo o que se exige de uma obra, sem que se pense na natureza de sua matéria.

Tudo o que se problematiza numa obra é pela mediação da linguagem. A obra não existe a não ser em palavras; ela é um ser de papel preenchido pelas palavras e pelo que delas emana; apropria-se do espírito da linguagem e origina-se de si mesma, levando a elasticidade da palavra para sua forma; não é apenas uma sequiência de palavras nem um depósito de signos, mas uma fonte de significação. E sempre dizer o que diz - recolocando o passado no presente, fazendo-o avançar e vibrar; conservá-lo no seu sentido de passado, mas revolvendo-o, envolvendo-o, resolvendo-o e devolvendo-o. Recapitular o passado de um signo é recuperá-lo, contê-lo em sua substância, filtrá-lo em sua sincronia, oferecê-lo em tempo de verdade particular e presente. A elaboração lingüística na obra - o que lhe dá a possibilidade de existência - é, então, um re-produzir a realidade; $o$ texto é a experiência manifesta de tudo aquilo que estava latente no objeto a formar. Formado, ainda é uma ironia: pleno de escolha subjetiva, deve ser visto como plano objetivo. Sua única obrigação é a manifestação de um paradoxo: claro, definido, equilibrado e tenso, deve proporcionar um gozar reflexivo num espaço/tempo infinitivo e recursivo, como recursivos sāo os estatutos por ele questionados, que se movem entre uma essencialidade plurissignificativa amortecida em repertório apassivado (signo) que se ativa num trajeto de encadeamente verbal em busca de uma unidade significativa maior (texto), que deflagre uma realidade latente - produtora e fornecida (contexto) - ponto de chegada e de partida .

Quando se trata de estabelecer as duas realidades da ficção, é impossível conceber seus estatutos sem que se detenha no caráter intrínseco do elemento mediador e primordial de todo o processo ficcional: considere-se como ficção, sem distinção, a prosa e a poesia: ambas se utilizam de uma mesma matéria-prima, ambas são formas narrativas, uma construção dialética entre paradigmas e as relações entre eles. Sua manipulação por qualquer uma destas modalidades ficcionais depende de outros fatores, todavia externos ao problema da constituição de um texto: por um resultado final ou outro (texto-prosa ou texto-poesia) sempre se alçará um texto: pleno de significação, continente e conteúdo. Dois momentos literários bastariam como exemplo: os poemas em prosa de Baudelaire (Spleen de Paris) e o caráter de parte da prosa latino-americana contemporânea, repleta de procedimentos expressamente poéticos.

Esta identidade se dá ao nível da utilização das estruturas mínimas do repertório sígnico, que comporta a existência de níveis e aspectos. Ao significante corresponde um nível prosódico e dois as- 
pectos: o parad gmático e o sintagmático. Ao significado cabe um nível sintático e um aspecto semântico (1). O nível prosódico, em um texto-poesia, corresponde ao metro, à rima, à assonância, ao ritmo (ou à ausência deles), à institu ção dos versos e das estruturas estróficas; num texto-prosa, às personagens e situações. Os aspectos que lhe correspondem se objetivam por um processo de constituição: um trabalho alquímico e arquitetural na seleção dos elementos simples (parad gmas) e sua combinação em unidades complexas (sintagmas). Quanto ao nível sintático, num poema ou texto em prosa, corresponde aos temas, motivos, episódios - às tensões internas manifestadas pelo texto. Sua correspondência com o aspecto semântico se estabelece por decorrência: uma tensão se nivela sintaticamente em função de sua própria carga semântica.

Se pensarmos na arbitrariedade ou motivação existentes entre o significante e o significado de um signo, a caracterização dos níveis e aspectos se enriquece. O significado (que, como se verá, é enformado e concretizado por um contexto ideológico) se mostra anterior ao significante: é um conceito mental resultante de uma oferta contextual, e cujo suporte (sonoro ou gráfico) foi selecionado e desenvolvido por caminhos e meios arbitrários que lhe possibilitassem uma permanência no código. Construindo um texto (e reforce-se - prosa ou poesia), é um ob,eto motivado que se erige por processos de recorrência significativa interna a partir de uma significação exterior ao texto, mas nele interior zada em signos.

Se uma tradição literária afirma que a prosa é comandada por um caráter de representatividade recusado pela poesia, o que se constata é que os comandos se permutam: "a poesia comporta, ela também, elementos representativos; e a ficção (prosa), propriedades que tornam o texto opaco, não transitivo." (TODOROV, 1970b, p. 64) Assim, a poesia, representando, apodera-se de instrumentos pelos qua.s se manifesta a transitividade de sua linguagem; a prosa, carregada de opacidade, comporta-se intransitiva, sem deixar de representar E, nos dois casos, o que se vê exteriorizada é uma crise de amb.ência problematizada, porque mediatizada, pela própria linguagem . Agora, um dos dois comandos desaparece: prosa e poesia, iguais a texto possível, são o campo rigoroso da transitividade, que se manifesta enquanto dizer um dizer, significando-o.

(1) - Entre um poema, conto, novela ou romance (cada forma tem sua prosódia particular), há que se notar apenas diferenças qualitativas na funcionalidade de tais níveis e aspectos. 


\section{A ANÁLISE INTEGRAL - OS ESTATUTOS RECURSIVOS}

"Une littérature (. .) n'est et ne peut être qu'une exploitation de quelques unes des propriétés d'un langage."

Paul Valéry (2)

Propor os termos "texto" e "contexto" não basta: o texto é uma fala (linguagem) que se motiva enquanto se constrói, apoiando-se em dados fornecidos a priori pelo contexto. São duas realidades que participam de uma comunhão sob apenas uma condição: a mediação da língua. Não há a possibilidade de texto sem a existência prévia de um contexto que lhe forneça a significação; não há a possibilidade estética de um contexto sem um texto que o signifique. Mas não haveria um texto significativo e um contexto significado sem que, entre os dois, não se reconhecesse o elemento que os converte em obieto estético: a língua, o repertório de signos (PAZ, 1973, p.253/254), cuja conversão em linguagem tem, aqui, alguns aspectos apontados, tendo em vista o que se pretenda ter como instrumento para uma análise integral da obra.

Signo, texto e contexto: três instantes absolutos, mas redutíveis: o signo é a possiblidade de atualização do texto e a capacidade de concreção do contexto; o texto é a virtualização do signo e a conıtação do contexto; o contexto consubstancia o signo e denota o texto. Como se vê no gráfico abaixo:

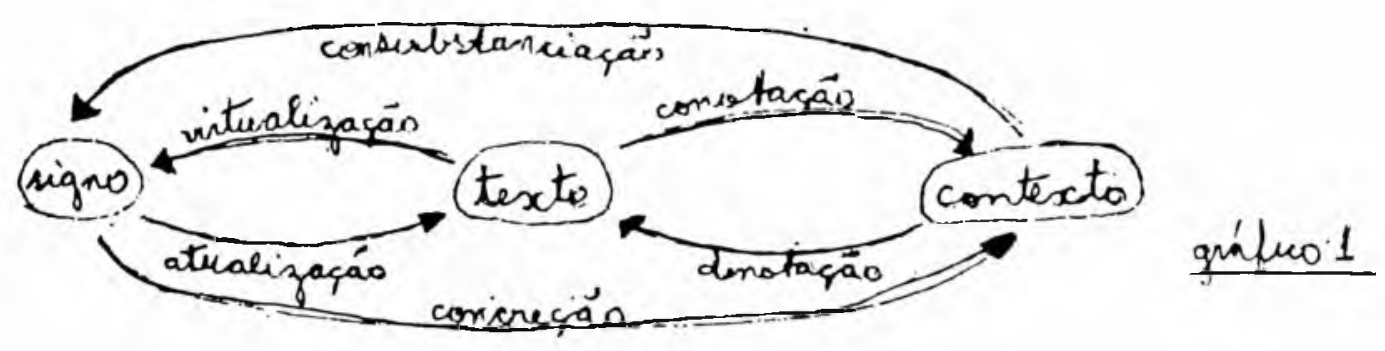

Mas o caráter desta redução só faz reconhecer a pertinência estruturadora dos signos, que garante a especificidade do texto e a inclusividade do contexto: se o texto virtualiza o signo, este o atualiza; se o texto conota o contexto, este o denota; se o signo concretiza o texto, este o corsubstancia. Esta reação em cadeia, incessante, pode objetivar o que Eco chama de "oscilaçāo contínua" (1974a, p.89): o

(2). - Regards sur le monde actuel et autres essais. 
contexto consubstancia o signo, o signo atualiza o texto, o texto conota o contexto, o contexto denota o texto, o texto virtualiza o signo e o signo concretiza o contexto. Estabelece-se, então, uma rede inextricável de significação, que torna impossível uma abordagem isolada de cada um dos estatutos: é necessário "considerar a obra como totalidade e unidade dinâmica" (TODOROV, 1970b, p.100), tanto no que ela tiver de mais concreto (o texto em si) quanto no que puder ter sido e tido extrapolado (o contexto evocado). Esquematizando o problema, vê-se que o signo, enformado pelo contexto, in-forma-se ao texto, que re-forma um contexto:

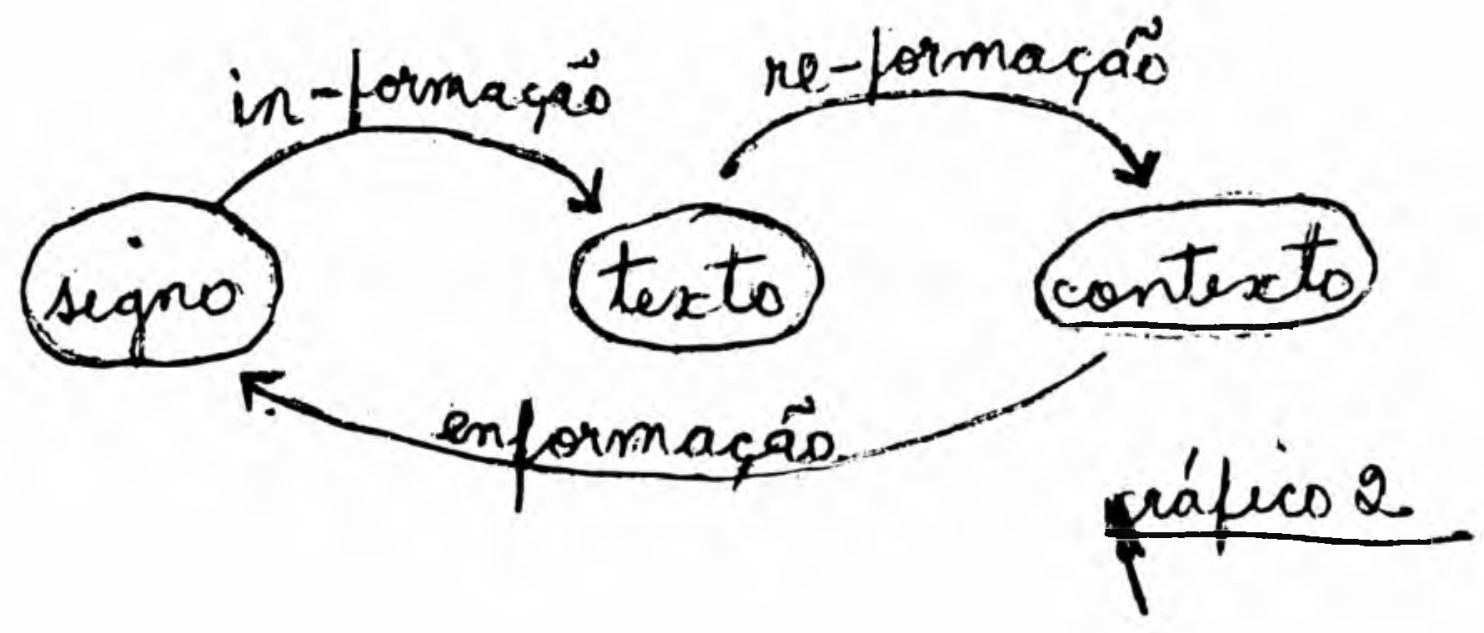

Toda a recursividade apontada propaga-se, assim, pela mediação da linguagem em seu estado primordial de signo. E, a partir disto, a análise de um texto e a referência a um contexto só poderiam ser feitas se fosse feita a "análise das unidades significativas do sistema literário, isto é, do conteúdo do sistema conotativo" (TODOROV. $1970 a, p$. 35) instaurado pela matéria-prima da obra. O texto - a Literatura, por extensão - surge, então, como o continente de uma realidade que "só existe na medida em que o homem a julga presente na linguagem" (CASAIS MONTEIRO, 1965, p. 127) medadora entre o texto e o contexto, porque, ao oferecer sua configuração abstrata e sua matéria perceptível, ela implica a motivação que é, "na trad ção saussuriana, a existência de relações não arbitrárias entre o significante e o significado" (GREIMAS, 1972, p. 23) Em outras palavras, se o sivno linguístico é arbitrário em relação à língua e à fala (onde ele existe virtualmente no repertório individual, ou, mais propriamente, porque tem existência consentida num contexto coletivo que lhe confere certas relações psíquicas arbitrárias), na medida em que se transforma na matéria básica de um texto torna-se motivado - fazendo do texto uma fala mediatizada - porque, atualizando-se, deve estabelecer relações bem marcadas e definidas, ainda que sua possibilidade polissêmica adquira dimensões imensuráveis. 
Assim, a matéria do texto é os disfarces (signos) de um mundo de disfarces (contexto), o que implica na instituição de três estatutos relativamente autônomos, porque recursivos. Cada um deles estabelecendo-se em sistemas: processos em andamento contínuo, com seus elementos em constante interdependência, com uma estruturação estática mas uma funcionalidade dinâmica; um ciclo de eventos garantindo uma permeabilidade interna dada pelo manejo particular dos signos (estatuto primordial) que constituem um texto (estatuto primeiro) que deflagra um contexto (estatuto segundo). Quando uma obra se manifesta à fruição, apresenta-se plena de significação em qualquer um de seus três estatutos/sistemas, sobrepostos, mas sempre cada um deles deslocado em relação ao anterior. Um deslocamento que procede da própria recursividade - uma contínua recorrência internalizada na obra, e que a garante e justifica.

O signo, estatuto primordial, resulta de uma associação psíquica arbitrária efetuada para preencher as possibilidades oferecidas pelo repertório contextual. E o produto final oferecido por um processo de consubstanciação e enformação de idéias, conceitos e valores aceitos passivamente e cristalizados, "em virtude duma espécie de contrato estabelecido entre os membros de uma comunidade" (SAUSSURE, 1972, p.22) em função de uma tradição. Compõe um sistema lingüístico na medida em que se comporta como um depósito entrópico que deixa ver a possibilidade de energia agindo com regeneração ou degeneração de seus elementos nos múltiplos modos de apresentação (falas) e vinculação (línguas) consagrados pela essencialidade de sua constituição. O signo deve ser encarado como a correlação combinada de um significante e de um significado, o primeiro sempre exprimindo o segundo. "Temos portanto o significante, o significado e o signo, que é o total associativo dos dois primeiros." (BARTHES, 1972. p.135) Mas não é, como poderia parecer, um sistema estático, um elenco de "palavras": se visto sincronicamente o signo apresenta uma movimentação interna de energias (veja-se, por exemplo, a possibilidade polissêmica de "penas"), do ponto de vista diacrônico as transformações se tornam mais evidentes: o tempo, agindo naturalmente sobre a língua acarreta um "deslocamento da relação entre o significado e o significante" (SAUSSURE, 1972, p. 89): o espaço conceitual de "brasa" tem sido reformado internamente. Podera ser visto sob esta perspectiva o problema da sinonímia: na medica em que um significado se torna tenso, outros significantes preenchem esta in-tensão. Dois outros fatos relevantes da regeneração de energias são a comutação ("na sela da palavras"/"na cela das palavras") e a découpage ("cavo algo" por "cavalgo") em que, se alguns fonemas se distinguem por traços acústico-articulatórios pertinentes, ss significados respectivos constituem um outro espaço semântico. For ou- 
tro lado, se pensarmos na degeneração dos signos, poder-se-ia examinar a questão das palavras-ônibus ("bacana"), em que um único significante se encarrega de uma associação com diversos significados. Nesłas possiblidades de regeneração ou degeneração, o contexto ideológ:co atua constantemente, o que garante a dinamicidade do sistema lingüístico. O signo é, então, um estatuto primordial, e o que dele releva, de sua constituição em um sistema lingüístico, é a estreita relação sempre mantida entre o significado e o significante, e a possibilidade maior de os fornecer que de os ver fenecer. E porque será a matéria-prima de um sistema posterior.

O texto compõe um sistema semiológico na medida em que se apropria dos elementos do sistema linguístico e se converte em um significante que adquire uma atualização em forma, pois que a "semiolugia só pode comportar uma unidade ao nível das formas, e nbo dos conteúdos; o seu campo é limitado, tem por ob;eto apenas uma linguagem, só conhece uma operação: a leitura ou deciframento." (BARTHES, 1972, p. 136) A limitação de seu campo provém da motivação entre os signos que o constituem. Parece, desta maneira, carecer de um significado próprio. Mas, propiciado por seu estabelecimento em linguagem, toma-o emprestado ao significado do sistema lingüístico. Eis a outra face da motivação, a que possibilita a re-produção de uma realidade anterior (um contexto), e que procura conotar esta mesma realidade em situação posterior. Este significado do texto - o conteúdo - e seu suporte formal comportam-se como um texto - o espaço da manifestação, entrelaçamento e ativação de potencialidades latentes - atrás do qual se esconde, ainda em estado de inconsciência, um sentido: a soria de sua forma e de seu conteúdo. Se no sistema linguístico o signo era o "total associativo" de um significante e um significado, no sistema semiológico os fenômenos são paralelos: o sentido é a soma de uma forma e de um conteúdo uma forma que só existe enquanto apropriação da totalidade de um estaluto primordial e um conteúdo que só se manifesta por recorrência a uma parte (o significado) dessa totalidade. É, então, um problema de simbiose e não de reafirmar uma dualidade inexistente: "na sealidade, não pode estar na forma nada que não estivesse já no seu conteúdo." (CASAIS MONTEIRO, 1965, p. 122) Uma outra afirmação confirmaria esta posiçāo: a aproximação dos conceitos de fábula e trama, propostos por Todorov (1970a, p. 42, 61 e 97) à "ousadia de uma excessiva simplificação" de Ricardou (1965, p. 57). Ao ccnteúdo corresponderia a fábula - matéria básica extraída do mundo - que se apresenta como um "objeto", passível de uma "síntese imediata" pela atitude do estruturador do texto, para quem o "ato de essrever faz surgir um mundo novo (trama) cuja estrutura é aquela mesma da linguagem" A forma se comporta como a trama, 
a maneira pela qual os fatos do mundo estão em relação entre si; é um "objeto descrito", passível de uma "síntese diferida": "um mundo fictício obtido pelo exercício da escritura, (que) opõe sua estrutura própria à de nosso mundo - e assim o coloca em questão." A trama (forma, significante) é, então, a elaboração episódica, ao nível prosódico e aspectos paradigmático (implica uma seleção) e sintagmático (decorrência de uma combinação) da fábula (conteúdo, significado, ao nível sintático e aspecto semântico). São duas existências de graus diferentes, mas que não se contradizem: alimentam-se reciprocamente, de maneira que "a forma (trama) organiza esteticamente sua matéria (conteúdo, fábula): o que era 'mundo' converte-se em 'linguagem' " (WELLEK \& WARREN, 1962, p. 306) Só agora a única operação possível para a Semiologia - "a leitura ou deciframento" encontra seu lugar $\mathbf{E}$ as exigências feitas ao texto (configuração, etc.) ficam destruídas quer se pense nos estatutos da forma (o signo do sistema lingüístico, o significante do texto, o objeto descrito, a síntese diferida) e do conteúdo (o significado do sistema lingüístico, - significado do texto, o objeto, a síntese imediata), quer se pense que o texto instaura um outro mundo, fictício, que mantém relações de re-produção com o mundo real apenas pela mediação da linguagem, numa "seqüência ordenada de elementos materiais e discretos que representa uma realização dum determinado sistema semiótico " (AGUIAR E SILVA, 1974, p.24) Sua característica principal é, então, como sistema semiológico, a de ser uma entidade que pode apenas uma coisa: tem algo próprio, diretamente derivado do sistema linguístico (o signo, tornado forma), mas, para que se manifeste integralmente, toma emprestado o necessário significado: eis seu deslocamento em relação ao sistema anterior, e primordial. E, pois, um estatuto primeiro, porque resultado da manipulação de elementos de um sistema anterior, primordial, e porque deflagrará um sistema posterior .

O contexto resulta da apropriação do sentido do sistema semiológico, agora alçado como a forma de um sistema ideológico que toma emprestado ao sistema anterior e primeiro, um conteúdo que se elabora em conceito: a soma desta nova forma e deste conceito constituem a significação - na medida em que é o segundo resultado de uma corrida em busca da realização da necessidade de comunicação (uso motivado de um código) e da informação estética (transformação, negação e destruição parcial efetuadas no interior desse mesmo código). E o mais complexo dos três estatutos/sistemas: além de fornecer aos signos lingüísticos a arbitrariedade entre os significantes e os significados e, ao texto, a motivação necessária para a concreção dos signos lingüísticos em elementos semiológicos, é capaz de se recolher nos primeiros, preenchendo-os de significados de naturezas as mais 
diversas - psicológicos, econômicos, políticos, sociais, religiosos, etc. - e, nos segundos, manifestar-se claramente por meio de um aprisionamento numa escritura que convida, propõe e instiga uma "leitura ou deciframento" Sua manifestação é, assim, a de uma metalinguagem, na qual fala com e sobre a linguagem do sistema semiológico e a língua do sistema lingüístico. Seu deslocamento em relação ao sistema semiológico é originado pelo fato de que, dele, retira um conceito que lhe faltava como parcialidade, porque emprestado anteriormente ao conceito (significado) do sistema lingüístico. Deve ser considerado, pois, um estatuto segundo, porque deflagrado por um sistema anterior, primeiro. Sua complexidade, aqui, se renova: sendo o espaço de uma fruição analítica do sistema semiológico é, também, o espaço de vetores divergentes para esta mesma fruição e uma fonte inesgotável de conceitos completados por imagens acústicas arbitrárias.

A recursividade - sugerida, insinuada e timidamente afirmada - pode agora ser sistematizada, em quatro dimensões: a) uma movimentação de avanços e retrocesso no plano dos significados; b) preenchimento dos espaços vazios que acompanham formas plenas; c) as transformações do signo, sentido e significação ao passarem do sistema linguístico para o semiológico para o ideológico para o linguístico; e d) as relações de redução apontadas nos gráficos 1 e 2 :

a) o conceito (significado) do sistema lingǘstico avança para o sistema semiológico, constituindo-se em seu conteúdo. Este conteúdo (significado do sentido), por sua vez, avança para o sistema ideológico, retornando à cond ção de conceito. Este conceito (significado da significação) retrocede e fornece sua substância ao conceito do sistema lingüístico. A identidade entre o conceito do sistema lingüístico e o do sistema ideológico não é apenas de terminologia: o conceito do estatuto primordial é o resultado de uma conscientização coletiva ou individual de elementos fornecidos pelo conceito do estatuto segundo. E neste instante que se opera o maior deslocamento em todo o processo de recursividade: o sistema ideológico (contexto) fornece uma quantidade infinita de conceitos (que serão realizados parceladamente) que serão preenchidos por um significante elaborado segundo as possibilidades estruturadoras do sistema lingüístico (signo): o significado linguíístico é, então, anterior a seu respectivo significante. O signo, constituído, pode ser, a partir daí, manipulado em um texto, agora em termos de conteúdo deste sistema semiológico. A constatação desta dimensão de recursividade entre os estatutos/sistemas pode fornecer elementos para a compreensão da intertextualidade: nada numa obra é "produto inédito de uma inspiração pessoal, feito sem alguma ligação com as 
obras do passado" (TODOROV, 1970b, p.11) Sendo uma linguagem, vale-se das combinatórias existentes previamente no domínio dos indivíduos que a realizam, inclusive o escritor, que, ao escrever um eles são a complexificação do texto: uma obra, editada ou não, passa a ser um ser no mundo, um indivíduo com corpo e idéias, à maneira dosindivíduos que a realizam, inclusive o escritor, que, ao escrever um (novo) texto vale-se de sua memória pessoal, da memória consensual e da memória literária, e elabora todas estas memórias na linguagem de seu texto, estabelecendo mais um elo da corrente recursiva;

b) o conteúdo do sistema semiológico (tomado ao conceito do sistema lingüístico) preenche a forma do texto, plena enquanto traz em si todo o estatuto primordial, mas ao qual falta, ao se erigir em estatuto primeiro, uma vibração existencial. O conceito do sistema ideológico (tomado ao conteúdo do sistema semiológico) preenche sua forma, também plena enquanto carrega em si todo o estatuto primeiro, ao qual falta, ao se alçar em estatuto segundo, uma conotação elástica. $O$ que se percebe é que, se no sistema lingüístico o significado se apresentava anterior a seu significante, agora as posições se invertem pela presença da motivação (que estrutura as obras, porque é parte de um projeto estético), a reger a "leitura ou deciframento": as formas (os significantes) dos sistemas semiológico e ideológico se mostrem anteriores, respectivamente, a seus conteúdo e conceito (os significados);

c) ao se constituir, o sistema semiológico toma sua forma ao signo (totalidade do sistema linguístico); o sistema ideológico toma-a ao sentido (totalidade do sistema semiológico): a significação, "totalidade associativa" de uma forma e de um conceito contextuais, permanece plena: não é passível de nenhuma redução - ao contrário, é a possibilidade fornecedora de novos conceitos ao sistema lingǘstico. Pode-se dizer que há uma tensão interna cada vez maior na passagem de um sistema a outro: o signo se reduz a uma forma, que se apropria do conceito do signo, formando um sentido - que é um novo signo; este se reduz a uma forma, toma para si o conteúdo do sentido, objetivando uma significação - que é um novo signo. Há, aqui, dois eixos recursivos bem distintos:

signo lingüístico $\rightarrow$ sentido semiológico $\rightarrow$ significação ideolósigno lingüístico $\rightarrow$ sentido semiológico $\rightarrow$ significação ideológica; significante linguístico $\rightarrow$ forma semiológica $\rightarrow$ forma ideológica, a identidade terminológica entre forma semiológica e forma ideológica é causal: a primeira (texto) deve, mediatizada pela linguagem, re-produzir a segunda (contexto);

d) a motivação entre os significantes e os significados é o elemento basilar da quarta dimensão da recursividade: o conceito (signi- 
ficado) do signo lingüístico é o espaço da consubstanciação dos elementos fornecidos pela significação; este conceito se atualiza no signo lingüístico e se in-forma na forma (o significante) do texto, ao mesmo tempo em que se retoma em conteúdo (significado) virtualizado; este conteúdo conota o sentido do texto e se re-forma na forma (o significante) do contexto, enquanto se retoma em conceito (o significado) denotado; este conceito concretiza e enforma uma significação que se reverterá na própria substância dos conceitos dos signos lingüísticos.

O quadro abaixo aponta as dimensões da recursividade:

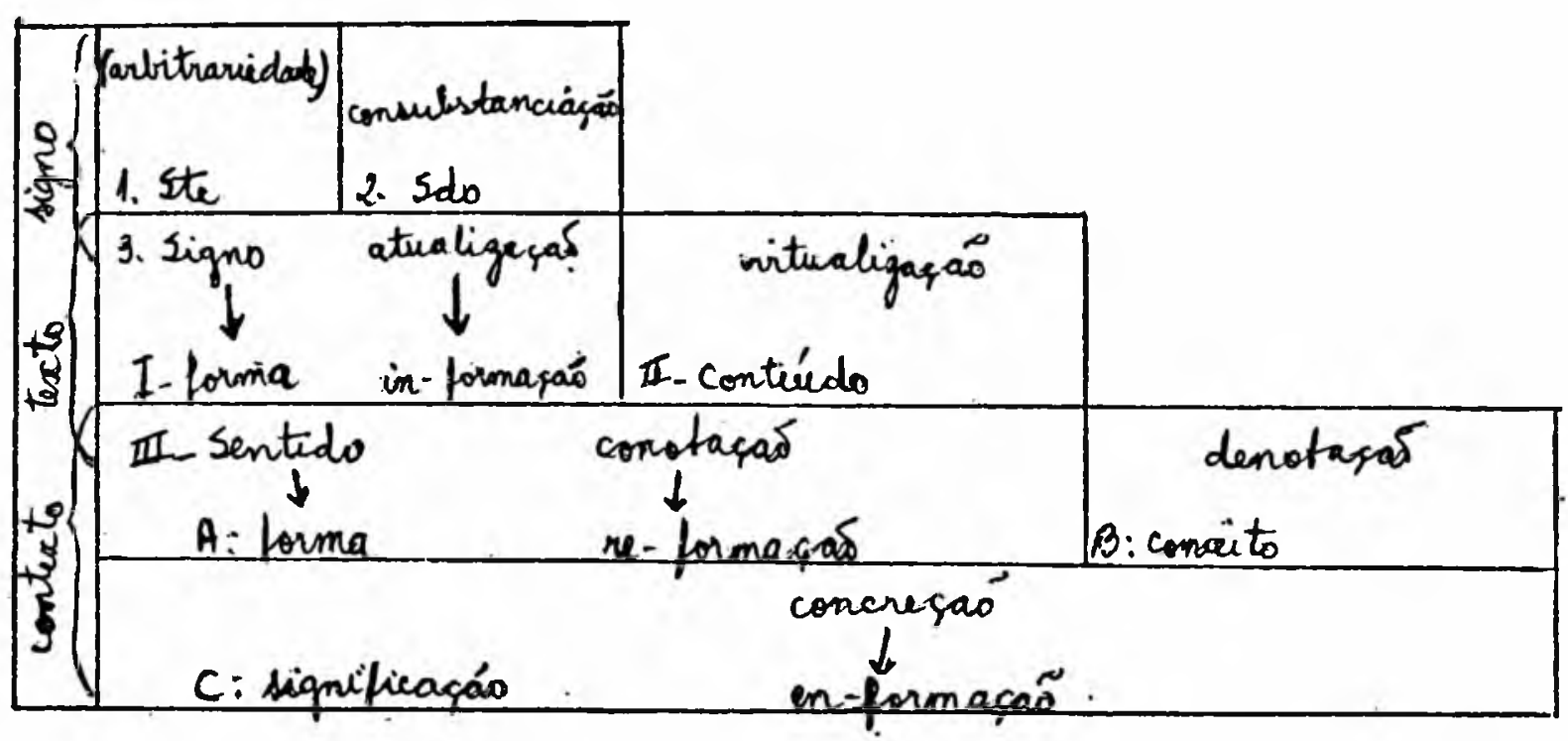

Todas as relações de reduçāo operam a partir de um conceito que se in-tensifica em forma e conteúdo semiológicos, forma e conceito ideológicos, até que reconsiga sua significação. O significante lingüístico permanece o espaço absoluto da arbitrariedade. Se, no eixo dos signos, as relações operam a partir da atualização do signo lingüístico, promovem a conotação do sentido (signo semiológico) e terminam com a concreção da significação (signo ideológico), e se, no eixo dos significados, as relações operam a partir da consubstanciação do conceito (o significado lingüístico) que se virtualiza em conteúdo no sistema semiológico e se denota em conceito (no sistema ideológico) que se reverte em conceito consubstanciado do signo lin- 
güístico, as relações finais de cada eixo são decorrentes: à consubstanciação (denotação + virtualização) sucede uma concreção (atualização + conotação): neste instante, pelas relações que ela estabelece ao se constituir em texto, a linguagem se mostra, plenamente, como o elemento mediador entre o texto (obra em si e o contexto (o exterior à obra). Resta verificar a funcionalidade desta mediação, feita pelas mínimas estruturas significativas: os signos lingüísticos.

Saussure (1972, p.142) aponta duas relações possíveis entre os signos: a "relaçãc associativa" e a "relação sintagmática" Jakobson (1975, p. 37-41) amplia esta posição e define o "duplo caráter da linguagem" A relação associativa implica em "seleção e substituição": "os signos estão ligados por diferentes graus de similaridade" A relação sintagmática "aparece em combinação e contextura": "os constituintes de um contexto têm um estatuto de contigüidade" A similaridade comporta eixos metafóricos; a contigüidade apresenta eixos metonímicos. Metáforas e metonímias dadas pela correspondência de suas relações com os respectivos aspectos paradigmático e sintagmático referidos na página 26 . Levando a concepção de Jakobson para o terreno do texto constituído percebe-se que o trabalho de combinação e contextura (relação sintagmática, metonímia) é o ponto fulcral da constituição do texto. A identificação das metonímias (correlação das posições tomadas frente aos signos tensos) possibilitará a verificação de que o texto mantém estreitos laços de contiguiidade em relação ao contexto. Não obstante, é preciso verificar que um sintagma (a metonímia, o texto) é o resultado de um encadeamento de paradigmas (as metáforas, os signos). Poderia parecer que uma metonímia fosse uma soma de metáforas: na realidade, a operação é inversa - a seleção paradigmática, que elabora metáforas (designase "mulher" por "rosa") é posterior à combinação sintagmática (produção de metonímia). A metáfora é, então, uma soma de metonímias: pense-se em "silêncio apertado", uma metáfora, resultado final, pensado a priori como "um silêncio cuja intensidade impossibilitasse uma manifestação existencial": mas perceba-se que o todo "apertado" só foi conseguido por processos de substituição das partes "intensidade" — "impossibilidade" — "desejo de existir", substituídas por apenas um paradigma que se combina com outro ("silêncio"), produzindo-se uma metonímia. Assim, um texto é um resultado metafórico final só compreensível se forem deslindadas as metonímias subjacentes. E será esta sugestão metonímica que estabelecerá a relação de contigüidade entre texto e contexto (uma parte /texto/ reproduzindo o todo /contexto/).

Esta relação de contigüidade poderia ser aprofundada: se na língua o significante é arbitrário em relação ao significado, no texto a 
arbitrariedade é substituída pela motivação: o texto é um signo motivado. Por ser basilarmente constituído de metonímias, a contigüidade estabelecida obriga a forma - o significante - do texto a reproduzir um contexto que lhe é anterior e posterior. Configuração, verossimilhança, imitação, representação, reprodução etc. passam a ser exigências repensáveis ao nível da verificação da linguagem metonímica do texto - linguagem que, se representa, configura, imita e reproduz, é por si mesma, valendo-se da "extensão e aplicação de certas propriedades de uma linguagem", contiguando.

Desta maneira, dizer-se "o texto e o contexto" é abrir perspectivas para se perceber quais as relações efetivas entre estes dois estatutos, desvendar suas estruturas semiológica e ideológica, incorporando à análise a verificação do valor da mediação proporcionada pelo signo lingüístico - ressaltando-se a relação de contigüidade que este possibilita entre o texto (objeto final) e o contexto (evocado pela obra).

A abertura analítica oferecida por este tipo de trabalho ultrapassa os limites da descrição estruturalista e se vê ampliada por uma interpretação de intenção globalizante, que se afirma sobre a intelecção dos signos (sistema lingüístico) - especificando sua manipulação como constituintes de um texto (sistema semiológico) - e se volta, pela mediação estabelecida no interior deste texto, para a captação dos valores ideológicos do contexto exterior à obra, procurando estabelecer, até, uma dimensão mítica possível na transposição deste contexto (um objeto neutro a ser manejado conforme escolhidos instrumentos de composição) para um espaço literário próprio - o texto (um objeto individualizado).

A análise integral de um texto envolve, então, o deslindamento de seus mecanismos de composição - sua alquimia verbal, sua arquitetura formal, sua carpintaria metonímica - em busca não apenas de um sentido, mas de uma significação. Se, como foi proposto com a afirmação de Valéry, uma obra não pode ser vencida senão por um mergulho profundo nela mesma, em sua linguagem, é preciso, no entanto, e por esta mesma opção, aceitá-la em todo seu complexo recursivo e, preso a ele, realizar uma operação de dissecção que se sobrecarrega, como o próprio texto, de uma ironia e um paradoxo: é com o estilhaçamento da obra que se consegue, com um reagrupamento dos estilhaços, uma visão total desta obra. Esta visão total, uma "análise imanente" (ADORNO, 1973, p. 76) da obra, à procura de uma unidade que só pode ser pensada como "uma que sofre a tensão entre seus momentos" (ADORNO, 1973, p.97), deve partir de uma desconfiança do objeto a ser analisado: a penetração neste objeto só será possível por uma hesitação dialética que se coloque do 
ponto de vista do tetxo (um tesouro roubado ao sistema lingüístico) e, dentro deste texto, esclarecer $o$ sentido do roubo, elucidando-lhe a linguagem contígua a um contexto que lhe forneceu a significação: entra-se no texto (sistema semiológico) e chega-se ao contexto (sistema ideológico) via metonimização do signo (sistema linguiístico).

\section{A ANÁLISE CONTEXTUAL - AS BANDEIRAS DES- FRALDADAS}

Afirmar que "o texto é o contexto" é considerar o objeto individualizado texto passivel de uma opacidade total que o transforma no próprio contexto, um objeto neutro. Supor que "o contexto é o texto" é ver neste texto uma transparência tão grande, de maneira que ele se manifeste apenas referencial. Nos dois casos, o composto nurn texto não é mais o que ele evoca (um trabalho de elaboração lingüística do objeto evocado) mas sim o próprio objeto evocado. Trata-se de fazer valer, com exclusividade, uma similaridade inexistente: o texto como o espaço do contexto, a linguagem encarregada apenas de uma função referencial, o significado entendido como o real. Ora, o objeto evocado é neutro, justamente na medida em que é capaz de fornecer uma gama inúmera de vetores de significação sem, no entanto, pretender que apenas um deles seja o único. Esta visão analítica se distorce ao sobrepor esta neutralidade ao texto, invalidando-o como forma e fazendo-o valer apenas pelo conteúdo. O texto é considerado como o espaço da motivação entre significantes e significados, mas vale-se apenas dos significantes na medida em que sejam os suportes gráficos dos significados, não se considerando que estes apenas existem em função da natureza motivadora do eixo conceito lingüístico $\rightarrow$ conteúdo semiológico $\rightarrow$ conceito ideológico. O primeiro termo passa a ser um significante, o segundo se estabelece como o significado que the corresponda (motivado e posterior); ao conceito ideológico confere-se o valor de um "total associativo" dos dois anteriores. Mas apenas o conteúdo semiológico (o significado desta visão) se apresenta capaz de manifestar uma mensagem: seu significante, (consubstanciado e ignorado) é imediata e simultaneamente considerado virtualizado e obrigado a denotar um conceito - função específica da mensagem referencial. Sem ambiguidades, este texto é pretendido como substituto do real: a mediação lingüística e os eixos recursivos não são verificados. Existe apenas uma possibilidade de realização do texto: aquela que o vê como uma fonte segura de informação ideológica sobre a sociedade, um testemunho de suas transformações, a denúncia simplista dos fatos sociais políticos, morais, religiosos, econômicos, folclóricos, históricos. E, a partir da constatação de sua presença no texto, são colhidos dados para a comprovação de teses políticas, econômicas; reforços para campanhas de de- 
fesa (ou ataque) de normas morais, religiosas. Textos assim analisados são erigidos em monumentos ideológicos e passam a ser os efeitos de causas não literáiras: a análise (uma operação posterior) atribui ao ato de escrever a obra (um trabalho anterior) uma função extrínseca à literatura, determinando-a por causas externas. As análises cessam quando se estabelece a verdade (ou inverdade) do meio social real (e não o "meio social" do texto, re-produzido com dados do real ou não) e quando se consegue provar, a partir do e no texto, as verdades das ciências que sistematizam em campos diferentes as parciais verdades do hemem: o texto se impõe objetivamente, explicado por fundamentos psicológicos, físicos, metafísicos, sociológicos, etnográficos, etc. Desta maneira, o ato de escrever torna-se um trabalho de natureza social, de elaboração de denúncias de momentos históricos determinantes: melhor escritor será aquele que souber fazer transparecer em seus textos as nervuras sociais, o denominador comum entre suas aspirações e as dos outros homens: chega-se, assim, ao óbvio de uma literatura vista como pretexto: "É notório que, no fundo, a Lukács o atrai mais a sociedade do que a literatura; e a política mais do que o estudo da sociedade." (IMBERT, 1971, p. 122) E suas análises de Balzac, têm, como resultado, não só revelar, erguendo o texto como prova, a falsidade de uma tentativa capitalista de solução de problemas do povo (Os camponeses - 1973a) e a problemática da mercantilização do espírito (Ilusões perdidas 1973b), mas também conferir a Balzac uma posição de honra entre os escritores realistas. O texto é a prova cabal de um crime denunciado; o escritor, o assassino redimido pelo conhecimento profundo do processo histórico; o crítico, o juiz parcial que, além de absolver o acusado, o acumula de medalhas e galardóes. Mas tais considerações sobre um texto, presentificado sempre como um "microcosmo artístico de um macrocosmo social" (IMBERT, 1971, p.123), eliminam quase toda a possibilidade de um reconhecimento consciente da potencialidade artística de um escritor Se Marx, Lukács e Malenkov reconhecem ser o "tipo" um elemento fundamental para a feitura de um romance realista, por outro lado, em termos de análise de um texto como arte literária, param por aí: "o problema do tipo é sempre um problema político" (Malenkov, in IMBERT, 1971, p. 123). Constatada a existência dos "tipos", a análise se farta a considerar o ato de elaborar tipos: resta vê-los na extensão do texto e, principalmente, na intenção que encarnam.

Este "encarnar" situa-se na base da "teoria do reflexo"; "para todo o grande escritor, o verdadeiro critério da grandeza literária era sempre a fidelidade frente à realidade, o apaixonado desejo de uma reprodução completa e real da realidade" (LUKÁCS, 1973c, p. 217) Esta paixão manifesta a exigência do partidismo político do es- 
critor, em seu sentido amplo, não necessariamente marxista, que, se não anula o ecletismo dos estatutos do texto e do contexto, pretende, no entanto, que o escritor se engaje na arquitetura dos "tipos" elegidos: se não há a necessidade de um engajamento político, há, por outro lado, a exigência de uma fidelidade ao instrumento composicional "tipo" - "sempre um problema político" Se um "método é sempre necessário para construir um objeto" (MACHEREY, 1971, p. 13), então este objeto individualizado - o texto - é uma "realidade secundária, segunda, o que não significa que não exista em virtude de leis que lhe sejam próprias" (p. 56): pelo fato de se apropriar de elementos externos à literatura, define-se como trans-realidade na medida em que, para ser decodificado e reconhecido, precisará deixar à mostra os mesmos elementos que o corporificaram: uma certa ilusão se convenciona no texto, mas é justificada por significações ideológicas determinantes. E ideologia, neste caso, é o trabalho de se retirar apenas uma máscara dentre todas as que cobrem o texto.

Este tipo de análise, de pretensões altamente esclarecedoras deslindamento do passado para que melhor se compreenda o presente, e sua viabilidade ou não - fundamenta-se, também, em farta instrumentação psicológico-psicanalítica. Da verificação do psiquismo das personagens (os paradigmas de um texto-prosa) retém-se apenas seu desenvolvimento no encadeamento sintagmático da trama para que se confirme traços, freudianos ou não, e para que, inclusive, e num desejo ainda altruísta, sejam abordados aspectos positivos ou negativos constatados nas personagens e nos indivíduos reais: há a formação de verdadeiras cruzadas "moralizadoras" - os traços positivos são realçados e incentivados, os negativos são acusados e desvalorizados. Quando, ainda, um crítico contextual, valendo-se da Psicologia, faz da obra uma via "para penetrar n apsique do autor", a debilidade de seu trabalho, em termos do estético procurado, se mostra mais visível: "a Literatura se reduz a simples sintoma, e o autor constitui o verdadeiro objeto de estudo." (TODOROV, 1970b, p. 159) Uma análise contextual pode, ainda, apoiar-se em outros paradigmas - os fatos históricos - e reduzir o texto literário à posição de um manual de história. A referencialidade volta a ser o lugarcomum da autonomia reduzida: ler Guerra e paz de Tolstoi e se equilibrar numa análise que se firme sobre o pano de fundo histórico; ler Mensagem de Fernando Pessoa e apanhar certos índices e, com eles, confirmar as histórias de Portugal.

Sociologia, Psicologia, História, o escritor as conhece, pelo menos o empírico suficiente para fazer vibrar em tudo o seu texto: fazer destas ciências o ponto de partida e chegada de uma análise apenas 
contextual - implicando, obviamente, uma posição ideológica frente a um elemento francamente ideológico - é elaborar sociologismos, psicologismos, historicismos, e não considerar que a função deste crítico (erigido em sociólogo, psicólogo/psicanalista, historiador) seria "reencontrar o caminho pelo qual a realidade histórica e social se exprimiu através da sensibilidade individual do criador" (Goldmann, in BASTIDE, 1971, p. 23) - uma nova posição dentro desta perspectiva sociocontextual e que, inclusive, considera o problema da recursividade dos sistemas na escrituração de um texto, como bem o comprova Sartre (1965, p.115): "a obra de arte não é um sonho, é um trabalho; em consequência, é um combate com a realidade, uma realidade que é perfeitamente verbal"

\section{A ANÄLISE TEXTUAL - OS ALICERCES À VISTA}

Se a intenção de uma crítica contextual se alarga à procura de "homologias estruturais" entre o contexto e o texto, a crítica textual, num paradoxo interno, enquanto amplia sua instrumentação, reformulando os conceitos manejados, parece fechar-se cada vez mais sobre seu objeto: a linguagem do texto. O new criticism e a crítica temática propugnavam uma absoluta prioridade ao texto-em-si, no que são seguidos por formalistas, estruturalistas e semiólogos. Aqui, à medida em que novos nomes aparecem, as teorias se complicam e uma lista cada vez maior de termos é formulada: a "in-tensão" de Tate, a "plurisignation" de Wheelwright, as "redes de significado" de Richard, a "visão integradora" de Starobinski; o "sistema de fatores correlativos" de Tinianov, o "motivo" e a "motivação" de Tomachévski, as "funções básicas" de Propp, a "classificação tipológica" de Vinogradov, a "tipologia das formas narrativas simples" de Chklóvski e Eichenbaum (TODOROV, 1970a, p. 27-50); a "semánalise" de Kristeva, a "isotopia" de Greimas, o "geno-texto" e o "feno-texto" de Saumjan/Soboleva, a "categoria situacional" de Geninasca, os "semantic markers" de Katz e Fodor, as "isotopias classemáticas, semiológicas, semêmicas ou horizontais, metafóricas ou verticais, semânticas e lexicais" de Rastier (GREIMAS, 1972). Se para o estruturalismo a estrutura é uma pré-significação (e o texto-enquanto-movimento seria a arquitetura dos significantes), e para o new criticism a estrutura é dada pelo conjunto dos significados, o divórcio dos elementos participantes do "total associativo" signo concorre para a afirmação de uma redução situada entre dois fogos, numa mesma tendência crítica: se a estrutura é dada, por um lado, pelos significantes, e, por outro, pelos significados, ela é passível de uma formulação tautológica: a estrutura é a estrutura, analisada sob perspectivas diferentes. Igualmente, se "o texto não é o contexto", o texto não é outra coisa senão texto; se "o contexto não é o texto", convém lembrar que um contex- 
to só se manifesta através de um texto - o ideológico não é o semiológico, mas só existe enquanto constituído em texto. Assim, um texto é sua própria estrutura e, ao mesmo tempo, dos elementos reais que o tornam fictício. Nas análises estruturais, o texto vale pelos significantes e as relações estabelecidas por eles; os new critics tomam a rede de significados como o significante do signo texto. Por uma atitude ou outra, o elemento significação (o contextual, o ideológico) não é observado: a forma prevalece sobre o conteúdo.

Se para Barthes (1974b, p.146) a "poesia é um clima" convém verificar que este "clima" é assegurado pelo contato com os significantes do texto que, em seu encadeamento, produzem a significação decorrente da convergência dos significados anteriores a eles, mas só catalogados a posteriori. Barthes (1970, p. 162) afirma que "a obra é sentido suspenso: ela se oferece com efeito ao leitor como um sistema significante declarado" Esta "suspensão do sentido" é o "clima" onde se "vê o significante ligado, como que de perfil, a alguns significantes virtuais dos quais ele está ao mesmo tempo próximo e distinto" (p. 46): esta ubiqüidade do significante é que proporciona o prazer do texto, quando "uma espécie de exatidão maníaca da linguagem" atribui ao texto o caráter de um "artefato lexicográfico" (BARTHES, 1974a, p. 64 e 66). Desta maneira, o texto é o "silêncio que se diz em palavras" (MELO E CASTRO, 1973, p. 9-10) "silêncio" que subsiste por "suspensão" num "clima" só possível pelas "palavras" (a face significante do signo) e seus processos de estruturação.

Poder-se-ia recordar o capítulo "Semântica da metáfora" (1974b) em que Eco trata de uma "substituição metafórica particular identificada no Finnegans Wake" (p.78) para perceber a que "artifícios diabólicos" o crítico recorre para penetrar no universo do sentido concentrado no manejo dos significantes: "sang + sans + glorians + Sanglot + riant dá 'Sansglorians'" (p.83); ou então um "ensaio de leitura de Rimbaud" em que Claude Zilberberg (in GREIMAS, 1972, p.140-154), analisando o poema Bonne pensée du matin estabelece uma nova estrutura estrófica (um novo "esquema narrativo") a partir de oposições aos níveis sintático, fonético, léxico e tipográfico presentes na "armadura semiótica do poema"; ou, ainda, As leituras das isotopias espaciais em ROTAÇÃO de Murilo Mendes (DURIGAN, 1974, p.117-143).

O que se percebe é que, se a crítica contextual atribui ao objeto analisado uma força retórica (ou simplesmente informativa) sem reconhecer no texto suas qualidades real e exclusivamente literárias, por outro lado, a crítica textual torna-se, cada vez mais, um campo para iniciados que, por caminhos-instrumentos-gráficos sempre mais sofis- 
ticados (se bem que, com este procedimento, levantem a planta baixa de um texto, valorizando - sem, no entanto, conferir-lhe medalhões - o autor), estabeleçam apenas o sentido, e não a significação do texto. Interrompem o trabalho a meio caminho: bastaria somente que se atentasse para a relação de contigu.dade patente entre o sentido (texto) desvendado (a linguagem é sempre esmiuçada às últimas consequências) e a significação (contexto), para que se conseguisse uma análise integral deste texto. Instrumentos não faltam: seu material é o suporte formal; bastaria considerar-lhe a consubstanciação significativa, e, em decorrência, penetrar nos eixos de recursividade para que se obtivesse uma visão global da obra: do texto (e o caráter mediador do signo, estilhaçado cerebralmente) ao contexto, e de novo ao texto, para a confirmação das hipóteses levantadas.

As análises textual e contextual - a primeira explorando o sentido, a segunda assinalando o óbvio da significação - mutilam o texto, cuja característica real é a de não ser apenas sentido, nem apenas significação, e sim um sentido que significa, oculto por uma elaboraçāo linguística que o revela, já que "a função da escritura do romance (ou outra narrativa) é colocar a máscara e, ao mesmo tempo, apontá-la." (BARTHES, 1974b, p.136) Na atitude de mascarar e apontar o disfarce, disfarçadamente, está o problema da Semântica (magia do signo, alquimia do verbo, arquitetura da forma, carpintaria do conteúdo - a construção de um sentido em busca de uma significação pressentida, por processos metonímicos): relevando-a (análise contextual), ignora-se a especificidade literária, colocando a obra no plano do, por exemplo, discurso filosófico; relegando-a (análise textual), elabora-se uma descrição da obra, recusando a pertinência dos temas para a crítica literária (TODOROV, 1970b, p.99-100).

\section{A SLPERPOSIÇĀO ALTERNATIVA - O FADO HETERO- GENEO}

As possibilidades de análise de um texto foram esgotadas e, como se leu, um maior número de páginas tateia, rebuscando-se um pouco, o estabelecimento de critérios suficientemente gerais para a descoberta de um caminho crítico prático que englobe o texto ao contexto (de onde eie saiu, para onde ele volta), tocando em implicações consideradas imediatas, e que permitisse submeter, sob uma definição comum, a prosa e a poesia. Se a análise chamada integral, de filiação crociana, afirma que "a arte é fundo com forma ou forma com fundo" (IMBERT, 1971, p. 208), o dimensionamento exposio neste trabalho é uma visão (não tão) pessoal do problema, uma exposição sintética de experiências e esforços experimentados em pequena criação: foi um processo de enquadramento de uma vivência 
que sobrevive dentro de uma memória que engloba o não projetado, o nascido e o analisado. A questão, agora, é verificar o destino que uma obra teve, a verificação de parte de um acervo crítico resultante de pontos de vista diferentes aplicados ao ato de frução analítica de um texto, unindo-o ou não ao contexto, estabelecendo ou não a elaboração lingüística como elemento mediador. A questão, agora, não vergentes: o problema é que opções extremadamente textuais ou contextual ou integral: quando se afirma "o texto e/ou o contexto", a visada é a penetração da memória (escrita) deixada pelos textos fruídos, de uma maneira ou outra. Embora se reconheça que análises meramente contextuais ou textuais não são atitudes de real reconhecimento do caráter verbal e transverbal da literatura, sabe-se que a análise integral não é "a boa tendência que procura uma mistura equilibrada das duas tendências, numa dosagem racional do estudo de formas e do estudo de conteúdos. A própria distinção entre forma e conteúdo deve ser ultrapassada." (TODOROV. 1970b, p.100) Mas as visadas textuais ou contextuais são a concretização da verificação da sinceridade ou do senso de realidade do escritor em direções divergentes: o priblema é que opções extremadamente textuais ou contextuais oferecem visões parciais e, em alguns casos, deformadas. Um avanço globalizante pretende ser a "Gramática do Decâmeron" de Todorov, em que são acentuadas as possibilidades metafóricas (somas de metonímias) do verbo punir, visto semanticamente mas à procura de elementos que configurem um contexto social em que as leis são transgredidas, respeitadas ou burladas, e, também, a caracterização de "categorias primárias" e "secundárias" "que permitem definir as paittes do discurso" e "as propriedades dessas partes", respectivamente. (1970a, p.140): é uma tentativa de, ainda usando o texto como pretexto, conseguir ir além de uma análise meramente formal (textual) para, através dele, penetrar numa realidade social (contexto) e verificar como este exterior se encontra contiguado na obra.

Mas trabalhos deste tipo estão sendo apenas palpados: mesmo o projeto de Todorov se atém, basilarmente, em perspectivas formais. E se os enfoques textuais ou contextuais restringem a totalidade que emana do texto, não significa que haverá a necessidade de gênios críticos: apenas um uso sensibilizado e conceitual de "todas as disciplinas possíveis - história, sociologia, filologia, psicologia" (IMBERT, 1971, p.209) para que se recupere toda a obra - a obra como u?n todo: um trabalho crítico, e não apenas a simpatia de gosto ou a objztivação de teorias pessoais ou socializantes. E enquanto o futuro não se presentifica, uma penetração na memória (no memorial) da crítica bem mostraria o fado heterogêneo atribuído a uma obra: uma superposição alternativa segundo um enfoque sobre o texto e/ou o contexto. 
Grande Sertão: Veredas tem sido penetrado por um ou outro flanco, ou pelos dois. A análise de Walnice Nogueira Galvão (1972) centra-se em "um estudo sobre a ambigüidade" (p . 3) fornecido pela "matéria" (conteúdo) da obra, desdobrada: "uma, a matéria historicamente dada, que está na consciência da cultura; outra, a matéria imaginária" A primeira é "a matéria do sertão, com o homem pobre do meio rural brasileiro, seu estilo de vida, sua maneira de enfrentar o mundo, o sistema de dominação vigente, a violência que o garante"; a segunda é a própria composição do romance, que "repousa na seleção de um monólogo que introduz, ao nível da narração, uma dupla perspectiva, que é a do narrador-personagem" (p. 12): a análise aproveita a segunda matéria ("a linguagem e a fala") na medida em que ela (o signo atualizando o texto, e este conotando o contexto) possa concretizar o que "é privilegiado no romance (:) um dos aspectos desse meio, qual seja o cangaço, com o jagunço como figura central" (p. 12)

Pedro Xisto (1970, p.7-39) parte "à busca da poesia", numa "revisão dos conceitos diferenciados de prosa (artística) e poesia" (p. 7): percorre todo o romance à procura da "expressão poética" possibilitada pela "palavra, como entidade" (p. 10): "ubiquação enfática de preposições ou de locuções prepositivas e adverbiais" (p.10); "autonomia e (...) multiplicada força denotativa de simples adjetivos articulares"; "a força - toda contida e pessoal - de um pronome"; "a prosa fluvial, torrencial, multidimensional, arrebentando as comportas da gramática" (p. 11) - a "revitalização" (p. 15) dos fatos da vida pela elaboração lingüística.

A análise de Augusto de Campos (1970, p. 41-70) procura pontos de contato, no plano semântico da obra, com o Finnegans Wake de Joyce, acentuando que "os grandes conteúdos do Grande Sertão, como os de Joyce, se resolvem não só através da, mas na linguagem" (p. 42). Uma análise do "esquema circular, da narrativa que propõe um retorno sobre si mesma" - a versão e a reversão, o "corso, ricorso de Vico e Joyce nos lábios de Riobaldo" (p. 49) se encaminha, novamente, para uma verificação de desenvolvimentos de uma "temática de timbres" (p. 55), a propósito da elaboração linguística distribucional dos fonemas $/ n /$ e $/ d /$, com fixação de motivos musicais em demênio, redemunho, nonada e no nada, e exemplificação de preficado", do nome Diadorim ("Dia + adora + im" e "Diá + dor ficado", do nome Diadorim ("Dia + adora + im" e "Diá + dor + in" - p. 61).

A análise de Haroldo de Campos (1970, p. 71-76) repousa na maneira de Guimarães Rosa "considerar o problema da linguagem" (p. 71): novamente um paralelo com o Joyce de Finnegans Wake, acompanhado de Robbe-Grillet, Michel Butor, Pound, com ênfase no 
fato de que "não é a estória que cede o primeiro plano à palavra, mas a palavra que, ao irromper em primeiro plano, configura o personagem e a ação, devolvendo a estória" de um "onceiro, perdido na solidão dos gerais, que recebe em seu rancho a visita inesperada de um viajante cujos camaradas se extraviaram" (p. 73): a linguagem (os signos linguísticos) do "onceiro" são catalogados, aclimatados, explicados.

A análise de Manuel Cavalcanti Proença (1959, p. 153-241), ressalvada a modéstia do crítico, "troteando sem grandeza, camro afora, por seiscentas páginas sem capítulos" (p. 153), enfoca, em primeiro lugar, as personagens e as relações estabelecidas entre elas, em três planos (o subjetivo, o coletivo e o mítico), ressaltando o heroísmo de Riobaldo, e afirmando que "não há dúvida que se trata de uma epopéia (p. 161); em seguida, são verificados "aspectos formais" do romance, visando o enquadramento de uma "busca da oralidade" pretendida por Guimarães Rosa: agora são explorados os latinismos, arcaísmos, palavras eruditas, indianismos, sufixação, prefixação, transformações fonéticas, expletivos, pleonasmos, superlativos, aliterações, jogos sonoros, ordem sintática emocional, coliterações, rimas em consonância, rimas toantes, ritmo tônico, onomatopéias, multiplicação dos toponímicos, juntando todos estes procedimentos de elaboração linguística ao caráter épico através de uma exploração semântica de navegar, remar, travessia, mar

Cinco análises, cinco fados à espera de um ponto convergente:

a) o "estudo sobre a ambigüidade" perpassa a elaboração lingüística pretendendo chegar (e chega) ao contexto;

b) a "busca da poesia" se apoia na elaboração lingüística para estabelecer critérios de identidade entre prosa e poesia como textos;

c) a mediação lingüística desenvolvida por uma "temática de timbres" aproxima a decomposição de Diadorim ao trabalho de découpage procedido por Eco a propósito de "Sansglorians", no Finnegans Wake;

d) a análise da elaboração lingüística em primeiro plano pesquisa parte desta elaboração, a linguagem do "onceiro", uma personagem;

e) o "troteando sem grandeza" verifica aspectos textuais, contextuais e problemas de gênero, em capítulos separados, como se fossem ensaios isolados.

Nos cinco trabalhos verifica-se, como estatuto predominante, o reconhecimento do valor artístico do sistema lingüístico na efabulação do romance: Augusto e Haroldo de Campos se detém na caracte- 
rização do tratamento lingüístico; Walnice Nogueira Galvão avança até o contexto social; Pedro Xisto se afasta para a discussão de problemas estéticos; Manuel Cavalcanti Proença situa-se ora no contexto, ora no texto, ora se afasta para classificar o romance. Vasta memória crítica: é forçoso reconhecer que "o fato de que os juízos do crítico não se imponham como verdades universais, não quer dizer que sejam constituídos de fúteis experiências estéticas e valores ilusórios" (IMBERT, p. 215) Convém reformular este juízo em favor da análise integral: "experiências estéticas" variadas são pontos de vista ideológicos pessoais, não invalidam uma atividade crítica; mas reconheçise que "verdades universais" são apenas aquelas que façam da obra uma significação em todos os sentidos - a verdade total de uma obra, tudo aquilo que o autor quis fazer significar por meio dela - algo até hoje não realizado sobre, por exemplo, Les paysans, de Balzac: se Grande Sertão: Veredas recebe medalhões pela elaboração lingüística, os camponeses de Balzac ainda (?) não tiveram reconhecida a transcrição de sua fala, em 1844: apenas sua problemática social teri sido valorizada em análises contextuais.

Não obstante, o que se pode concluir é que, tanto no ato de criar quanto no de analisar, "as palavras ganharam uma autonomia que as coisas perderam" (TODOROV, 1970b, p. 177) em virtude da ampliação do número de coisas que cercam o homem. Mas em funçã̃o desse mesmo aumento é necessário reatá-las ao homem, colocando-as, cada vez mais, até definitivamente, no contexto de significação em que ele vive.

\section{BIBLIOGRAFIA}

ADORNO, Theodor $\mathrm{W}$

1962 "Discurso sobre lírica y sociedad", in Notas de literatura. Barcelona, Ariel.

1973 Notas de literatura. Rio, Tempo Brasileiro. (Trad. port.: Celeste Aída Galeão e Idalina Azevedo da Silva)

AGUIAR E SILVA, Vitor Manuel de

1974 "O texto literá:io e seus códigos", in COLÓQUIO/LETRAS no 21. Lisboa.

BARTHES, Roland

1970 Crítica e Verdade. São Paulo, Perspectiva. (Trad. port.: Leyla Perrone-Moisés)

1972 Mitologias. São Paulo, DIFEL. (Trad. port.: Rita Buongermino e Pedro de Souza). 
1974a O prazer do texto. Lisboa, Edições 70. (Trad. port.: Maria Margarida Barahona)

1974b Novos ensaios críticos/O grau zero da escritura. São Paulo, Cultrix. (Trad. port.: Heloysa de Lima Dantas e Annie Arnichaud e Álvaro Lorencini)

BASTIDE, Roger

1971 Arte e Sociedade. São Paulo, Cia Editora Nacional/EDUSP (Trad. port.: Gilda de Mello e Souza)

CAMPOS, Augusto de

1970 "Um lance de 'dês' do Grande Sertão", in Guimarães Rosa em três dimensões. São Paulo, Conselho Estadual de Cultura.

CAMPOS, Haroldo de

1970 "A linguagem do iauaretê", in Guimarães Rosa em três dimensões.

CASAIS MONTEIRO, Adolfo

1965 A palavra essencial. São Paulo, Cia Editora Nacional/EDUSP

DURIGAN, Jesus Antonio

1974 "As leituras das isotopias espaciais em Rotação de Murilo Mendes", in SIGNIFICAÇĀO $\mathrm{n}^{\circ} 1$.

$\mathrm{ECO}$, Umberto

1974a A estrutura ausente. São Paulo, Perspectiva. (Trad. port.: Pérola de Carvalho).

1974b As formas do conteúdo. São Paulo, Pe:spectiva/EDUSP (Trad. port.: Pérola de Carvalho).

GALVÃO, Walnice Nogueira

1972 As formas do falso. São Paulo, Perspectiva.

GREIMAS, Algirdas Julien

1972 "Pour une théorie du discours poétique", in Essais de sémiotique poétique. Paris, Larousse.

IMBERT, Enrique Anderson

1971 Métodos de crítica literária, Coimb:a, Livraria Almedina. (Trad. port.: Eugénia Maria M. Madeira de Aguiar e Silva)

JAKOBSON, Roman

1975 "Dois aspectos da linguagem e dois tipos de afasia", in Lingiǘstica $e$ comunicação. São Paulo, Cultrix. (Trad. port.: Izidoro Blikstein e José Paulo Paes).

LUKĀCS, György

1973a "Balzac: Los campesinos", in Sociologia de la literatura. Barcelona, Ediciones Península. (Trad. esp.: Michael Faber-Kaiser O:g.: Peter Ludz)

1973b "Balzac: Ilusiones perdidas", in Sociologia de la literatura.

1973 c "Introducción a los escritos estéticos de Marx y Engels", in Sociologia de la literatura. 
MACHEREY, Pierre

1971 Para uma teoria da produção literária. Lisboa, Editorial Estampa. (Trad. port.: Ana Maria Alves)

MELO E CASTRO, Ernesto Manuel de

1973 O próprio poético. São Paulo, Edições Quíron.

PAZ, Octavio

1973 "Los signos en rotacíon" in El arco y la lira. México, Fondo de Cultura Econômica.

PROENÇA, Manuel Cavalcanti

1959 "Trilhas no Grande Sertão", in Augusto dos Anjos e outros ensaios. Rio, José Olympio.

RICARDOU, Jean

1965 depoimento in Que peut la littérature? (Org.: Yves Bruin)

SARTRE, Jean-Paul

1965 depoimento in Que peut la littérature?

SAUSSURE, Ferdinand de

1972 Curso de Lingüística Geral. São Paulo, Cultrix/EDUSP (Trad. port.: Antônio Chelini, José Paulo Paes e Izidoro Blikstein)

TODOROV, Tzvetan

1970a As estruturas narrativas. São Paulo, Perspectiva. (Trad. port.: Leyla Perrone-Moisés).

1970b Introduction à la littérature fantastique. Paris, Seuil.

WELLEK, René e WARREN, Austin

1962 Teoria da Literatura. Lisboa, Europa-América.

XISTO, Pedro

1970 “Á busca da poesia”, in Guimarães Rosa em três dimensões. ZILBERBERG, Claude

1972 "Un essai de lecture de Rimbaud: 'Bonne pensée du matin' ", in Essais de sémiotique poétique. 